nghiên cứu của Mark Antal chỉ thực hiện trên nhóm răng cửa và răng hàm nhỏ, còn của chúng tôi được thực hiện trên cả các răng hàm lớn. Cho thấy rằng máng được sử dụng nhóm răng hàm lớn có kết quả tương đương nhóm răng trước và răng hàm nhỏ. Sự khác biệt sai số giữa các nhóm răng không có ý nghĩa thống kê.

Với kết quả này chúng tôi thấy rằng có thể sử dụng máng hướng dẫn vào phẫu thuật cắt chóp, theo cách cách đơn giản hóa phẫu thuật nhưng hiệu quả. Trong giới hạn của nghiên cứu, phương pháp mới được đánh giá dựa trên kết quả giai đoạn đầu sau khi phẫu thuật. Y học dựa trên bằng chứng, kết quả lành thương hoàn toàn và răng thực hiện chức năng bình thường sau cắt chóp có ý nghĩa cao nhất, do đó cần các nghiên cứu tiếp theo để dõi đánh giá kết quả lành thương về lâu dài.

\section{KẾT LUẬN}

Phẫu thuật cắt chóp với máng hướng dẫn và mũi Trephine có độ chính xác cao, an toàn, và thực hiện được với cả các răng hàm lớn. Phương pháp cần được tiến hành nghiên cứu nhiều hơn về kết quả lành thương sau phẫu thuật.

\section{TÀI LIỆ THAM KHẢO}

1. Trịnh Thị Thái Hà và cộng sự (2013), Nghiên cứu đặc điểm lâm sàng, x quang và nguyên nhân của các răng cần điều trị tủy lại. Tạp Chí $Y$ học Thực Hành - Bộ Y Tế. số 864 (67-70), 2013.

2. M. Antal et al. (2019), Accuracy and clinical safety of guided root end resection with a trephine: a case series. Head Face Med., vol. 15, Dec. 2019. DOI: $10.1186 / s 13005-019-0214-8$.

3. A. Chércoles-Ruiz et al. ( 2017), Endodontics, Endodontic Retreatment, and Apical Surgery Versus Tooth Extraction and Implant Placement: A Systematic Review. J. Endod., vol. 43, no. 5, pp. 679-686, May 2017. DOI: $10.1016 /$ j.joen.2017.01.004.

4. P. A. Gilheany et al. (1994), Apical dentin permeability and microleakage associated with root end resection and retrograde filling. J. Endod., vol. 20 , no. 1 , pp. $22-26$, Jan. 1994. DOI: $10.1016 /$ s0099-2399 (06) 80022-1.

5. S. Kim et al. (2006), Modern Endodontic Surgery Concepts and Practice: A Review. J. Endod., vol. 32, no. 7, pp. 601-623, Jul. 2006. DOI: 10.1016/j.joen.2005.12.010.

6. B. Krastev et al. (2020), Periapical Surgery. Review. Classic vs Modern Concepts. Int. J. Med. Rev. Case Rep., no. 0, p. 1, 2020. DOI: 10.5455/IJMRCR.periapical-surgery.

7. A. Tahmaseb et al. (2018), The accuracy of static computer-aided implant surgery: A systematic review and meta-analysis. Clin. Oral Implants Res., vol. 29 Suppl 16, pp. 416-435, Oct. 2018. DOI: $10.1111 / \mathrm{clr} .13346$.

8. F. J. Vertucci (2005), "Root canal morphology and its relationship to endodontic procedures," Endod. Top., vol. 10, no. 1, pp. 3-29, 2005. DOI: 10.1111/j.1601-1546.2005.00129.x.

\title{
ĐẶC ĐIỂM GIẢI PHẪU ĐộNG MẠCH TUYẾN TIỀN LIỆT TRỀ PHIM CHỤP MACH SỐ HÓA XÓA NỀN Ở BÊNH NHÂN TĂNG SẢN LÀNH TÍNH TUYẾN TIỀN LIỆT
}

\author{
Lê Thị Linh*, Trần Quốc Hòa**, Ngô Xuân Khoa** \\ Trần Sinh Vương**, Trần Lê Đình Duy**, Hoàng Văn Hồng***, \\ Nguyễn Tuấn Sơn****, Nguyễn Thái Hà Dương****
}

\section{TÓM TẮT}

Mục tiêu: Mô tả một số đặc điểm giải phẫu của động mạch tuyến tiền liệt trên phim chụp mạch số hóa xóa nền ở bệnh nhân tăng sản lành tính TTL. Đối tượng và phương pháp: Mô tả hồi cứu và tiến cứu trên kết quả chụp mạch số hóa xóa nền của 20 bệnh

\footnotetext{
*Trường Đại học Y khoa Vinh,

**Trướng Đại học Y Hà Nội.

*** Bệnh viện Đại học Y Hà Nội

****Trường $Đ H$ Y Dược - ĐH Quốc gia, Hà Nội

Người chịu trách nhiệm chính: Lê Thị Linh

Email: linhle240593@gmail.com

Ngày nhận bài: 20/8/2021

Ngày phản biện khoa học: 13/9/2021

Ngày duyệt bài: 2/10/2021
}

nhân nam có tăng sản lành tính tuyến tiền liêt tại khoa chẩn đoán hình ảnh, bệnh viện Đại học y Hà Nội từ tháng 8/2018 đến 8/2021. Kết quả: Trong 33 bên khung chậu tìm được 35 động mạch TTL (của 20 bệnh nhân), có 2 bên khung chậu có 2 động mạch TTL (chiếm 6,1\%), 31 bên khung chậu có 1 động mạch TTL (chiếm 93,9\%). Về vị trí xuất phát của 35 động mạch TTL theo phân loại của Francisco Canervalle, tỉ lệ ĐM TTL xuất phát từ loại I (thân chung bàng quang), loại II (nhánh trước ĐM chậu trong), Loại III (ĐM bịt), loại IV (ĐM thẹn trong), loại V (khác) lần lượt là $20 \% ; 2,9 \% ; 34,3 \% ; 31,4 \%$ và $11,4 \%$. Xơ vữa ĐM tìm thây trên DSA trong $11,4 \%$. Tỷ lệ ĐM TTL có hình ảnh xoắn vặn như lò xo là $71,4 \%$. Đường kính trung bình ĐM TTL là $1,49 \pm 0,12 \mathrm{~mm}$. ĐM TTL cho nhiều vòng nối với các cơ quan lân cận, ĐM TTL có thể cấp máu cho dương vất $31,4 \%$, túi tinh $17,1 \%$, TTL bên đối diện $37,1 \%$. Kết luận: ĐM TTL xuất phát 
từ động mach bịt hay gặp nhất. Vòng nối ĐM TTL rất đa dạng, có thể cấp máu cho dương vât, túi tinh, bàng quang, ĐM TTL bên đối diện... Do đó, cân nắm vững giải phẫu và biến thể của ĐM TTL khi điều trị tăng sản lành tính TTL bằng phương pháp nút mạch.

Tư khóa: Đônng mach tuyến tiền liệt, chụp mạch số hóa xóa nền, phân loại Francisco Canervalle.

\section{SUMMARY}

\section{ANATOMICAL CHARACTERISTICS OF PROSTATIC ARTERY IN PATIENT WITH BENIGN PROSTATIC HYPERPLASIA ON DIGITAL SUBSTRACTION ANGIOGRAPHY}

Aim: To describe anatomical characteristic of prostatic artery on DSA scan of patient with benign prostatic hyperplasia (BPH). Material and method: Prospective and retrospective study on DSA scan of 20 male patients with BPH at Radiology Center of Hanoi Medical University Hospital from August 2018 to August 2021. Result: On 33 pelvis sides scan of 20 patients which reveals prostatic artery, there are 2 pelvis sides have two PAs (accounts for 6.1\%), 31 pelvis sides have single PA (accounts for 93.9\%). In terms of origin among 35 PAs found, according to Francisco Canervalle classification, the ratio of type I (originating from common vesical trunk), type II (originating from anterior trunk of internal iliac artery), type III (originating from obturator artery), type IV (originating from internal pudendal artery) and type $\mathrm{V}$ (other origins) are, respectively: $20 \% ; 2.9 \% ; 34.3 \%$; $31.4 \%$ and $11.4 \%$. Atherosclerosis was observed in $11.4 \%$ of PAs. The "corkscrew" pattern was found in $30.4 \%$. The average diameter of PAs was $1.53 \pm 0.34$ $\mathrm{mm}$. Collateral circulations between PAs and other vessels were also observed: $31.4 \%$ of Pas anastomose with penile artery, $17.1 \%$ of PAs anastomose with branches supplying seminal vesicle, $37.1 \%$ anastomose with contralateral PA. Conclusion: The origin of type III is the most common variation in this study. The existence of anastomose of PAs indicates that common anatomy of PAs and its variations are essential factors affect the treatment of BPH.

Keyword: Prostatic artery, digital subtraction angiography, Francisco Canervalle classification.

\section{I. ĐĂT VẤN ĐỀ}

Nút ĐM TTL điều trị tăng sản lành tính TTL là phương pháp xâm lấn tối thiểu, thời gian phục hồi nhanh, ít nguy cơ biến chứng và được áp dụng ở Việt Nam cũng như trên thế giới trong những năm gần đây.

Tuy nhiên, trong số các kỹ thuật Xquang can thiệp mạch, nút động mạch TTL đã được chứng minh là một trong những kỹ thuật khó nhất do sự phức tạp của động mạch tuyến tiền liệt. Động mạch TTL có đường kính nhỏ, chỉ khoảng $1,5 \mathrm{~mm}^{1}$. Số lượng và nguồn gốc xuất phát của động mạch khổng hằng định, biến thể giải phẫu phức tạp, xơ vữa nhiều ở đàn ông lớn tuổi. Ngoài các vị trí xuất phát hay gặp nhất như động mạch thẹn trong, thân chung với ĐM bàng quang trên, ĐM TTL có thể xuất phát từ động mạch mông trên, trực tràng, sinh dục phụ, thậm chí từ động mạch chậu ngoài. Động mạch TTL có nhiều vòng nối phụ xung quanh như dương vật, bàng quang, túi tinh, trực tràng... nên việc nhận biết vòng nối bất thường của ĐM TTL với các ĐM khác là cần thiết để tránh nút tắc phải các cơ quan như bàng quang, trực tràng, dương vật...

Vấn đề mấu chốt đảm bảo thành công của phương pháp điều trị này là nắm vững giải phẫu của ĐM TTL. Vì vậy, chúng tôi tiến hành nghiên cứu với mục tiêu: mô tả một số đặc điểm giải phẫu động mạch tuyến tiền liệt trên phim chụp mạch số hóa xóa nền ở bệnh nhân tăng sản lành tính tuyến tiền liệt.

\section{II. ĐỐI TƯỢNG VÀ PHƯƠNG PHÁP NGHIÊN CỨU}

2.1. Đối tượng nghiên cứu. Trong thời gian $8 / 2018$ đến $8 / 2021$, chúng tôi đã thu thập được kết quả chụp mạch số hóa xóa nền động mạch tuyến tiền liệt của 20 bệnh nhân nam có tăng sản lành tính tuyến tiền liệt tại khoa Chẩn đoán hình ảnh, bệnh viện Đại học Y Hà Nội.

\subsection{Phương pháp nghiên cứu}

- Thực hiện nghiên cứu mô tả hồi cứu và tiến cứu.

- Mồ tả về đường kính, nguồn gốc, số lượng động mạch, tình trạng xơ vữa, hình dạng và vòng nôii của động mạch TTL.

\section{KẾT QUẢ NGHIÊN CỨU}

\subsection{Vị trí xuất phát động mạch tuyến} tiên liệt.

Bảng 1. Phân loai ĐM TTL theo FC.Carnevale.

\begin{tabular}{|c|c|c|}
\hline Type & Số lượng & Tỷ lệ (\%) \\
\hline I & 7 & 20 \\
\hline II & 1 & 2.9 \\
\hline III & 12 & 34.3 \\
\hline IV & 11 & 31.4 \\
\hline V & 4 & 11.4 \\
\hline Tống số & $\mathbf{3 5}$ & $\mathbf{1 0 0}$ \\
\hline
\end{tabular}

Nhận xét: ĐM TTL xuất phát từ ĐM bit chiếm tỷ lệ cao nhất $34,3 \%$, sau đó là từ ĐM then trong chiếm $31,4 \%$. Chiếm tỷ lệ thấp nhất là xuất phát từ ĐM nhánh trước ĐM chậu trong với tỷ lệ 2,9\%.

\section{2. Đường kính ĐM TTL.}

Bảng 2. Đường kính trung binh động mach TTL.

\begin{tabular}{|c|c|}
\hline \multicolumn{2}{|c|}{ Đường kính ĐM TTL (mm) } \\
\hline Nhỏ nhất & 0.61 \\
\hline Lớn nhất & 3.6 \\
\hline Đường kính trung bình & $1,49 \pm 0,12$ \\
\hline
\end{tabular}




\begin{tabular}{|c|c|}
\hline $\begin{array}{l}\text { Đường kính trung bình } \\
\text { động mạch TTL }\end{array}$ & $\begin{array}{l}\overline{x_{ \pm} \mathbf{S D}} \\
(\mathbf{m m})\end{array}$ \\
\hline Bên có 1 động mạch TTL & $1,55 \pm 0,13$ \\
\hline Bên có 2 động mạch TTL & $1,00 \pm 0,13$ \\
\hline
\end{tabular}

Nhận xét: bên có 1 ĐM có đường kính lớn hơn bển có 2 ĐM.

3.2. Số lượng động mạch tuyến tiền liệt mối bên.

số lưọ̣ng ĐM TTL

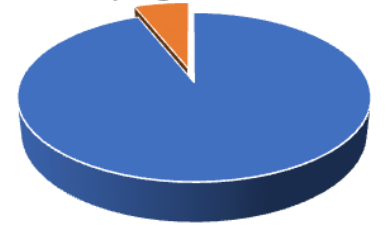

- 1 động mạch TTL 2 động mạch TTL

Biểu đồ 1. Minh họ số lượng ĐM TTL từng bên khung chậu.

Nhân xét: Tỷ lệ bên có 2 ĐM TTL chiếm 6,1\%, bên có 1 ĐM chiếm 93,9\%.

3.4. Hình dang $Đ M T T$

Bảng 4. Phẩn loại ĐM TTL theo hình dạng.

\begin{tabular}{|c|c|c|}
\hline Hình dạng & Số lượng & Tỷ lệ (\%) \\
\hline Có xoằn & 25 & 71,4 \\
\hline Không xoắn & 10 & 28,6 \\
\hline Tống số & $\mathbf{3 5}$ & $\mathbf{1 0 0}$ \\
\hline
\end{tabular}

Nhận xét: Tỷ lệ ĐM TTL xoắn như hình lò xo chiếm $71,4 \%$.

3.5. Xơ vữa.

Bảng 5. Phân loại ĐM TTL theo xơ vữa.

\begin{tabular}{|c|c|c|}
\hline Hình dạng & Số lượng & Tỷ lệ (\%) \\
\hline Có xơ vữa & 4 & 11,4 \\
\hline Không Xơ vữa & 31 & 88,6 \\
\hline Tống số & $\mathbf{3 1}$ & $\mathbf{1 0 0}$ \\
\hline
\end{tabular}

Nhận xét: Tỷ lệ xơ vữa ĐM TTL chiếm 11,4\%.

3.6. Vòng nối của ĐM TTL:

Bảng 6. Các vòng nôi của ĐM TTL với các tạng lân cận.

\begin{tabular}{|c|c|c|}
\hline & Số lượng & Tỷ lệ (\%) \\
\hline Có vòng nối & 19 & 54.3 \\
\hline Không có vòngnối & 16 & 45.7 \\
\hline Tổng & $\mathbf{3 5}$ & $\mathbf{1 0 0}$ \\
\hline
\end{tabular}

Nhận xét: Tỷ lệ ĐM TTL có vòng nối với các cơ quan lân cận hay gặp hơn (54,3\%).

Bảng 7. Tỷ lệ các loại vòng nôi bât thường của ĐM TTL.

\begin{tabular}{|c|c|c|}
\hline Vòng nối & Số lượng & Tỷ lệ (\%) \\
\hline Bàng quang & 1 & 2.9 \\
\hline Túi tinh & 6 & 17.1 \\
\hline Dương vật & 11 & 31.4 \\
\hline Trực tràng & 1 & 2.9 \\
\hline $\begin{array}{c}\text { Nhu mô̂ TTL } \\
\text { bên đối diện }\end{array}$ & 13 & 37,1 \\
\hline
\end{tabular}

\section{BÀN LUÂ̂N}

Trong 40 bên khung chậu được nghiên cứu, chúng tôi loại 7 bên khung chậu do không quan sát thấyĐM TTL hoặc không đánh giá đủ các đặc điểm về giải phẫu của ĐM TTL trên phim chụp mạch.Về vị trí xuất phát của ĐM $T T L$, theo phẩn loại của FC. Carnevale 2 , ĐM TTL xuất phát từ ĐM bịt chiếm tỷ lệ cao nhất 34,3\%, sau đó là từ ĐM thẹn trong chiếm tỷ lệ $31,4 \%$. Kết quả này cũng tương tự như nghiên cứu của các tác giả đưa ra phân loại trên ${ }^{2}$. Tuy nhiên,kết quả này so với nghiên cứu của Wang và cộng sự có sự khác biệt, tỷ lệ ĐM TTL xuất phát từ thân chung bàng quang (37.1\%) là hay gặp nhất, tiếp theo là từ nhánh trước ĐM chậu trong (31.1\%), sau đó mới đến ĐM thẹn trong $(24.2 \%)^{3}$. Trong nghiên cứu của chúng tôi, tỷ lệ xuất phát từ nhánh trước ĐM chậu trong rất thấp, chỉ gặp 1 trường hợp $(2,9 \%)$.

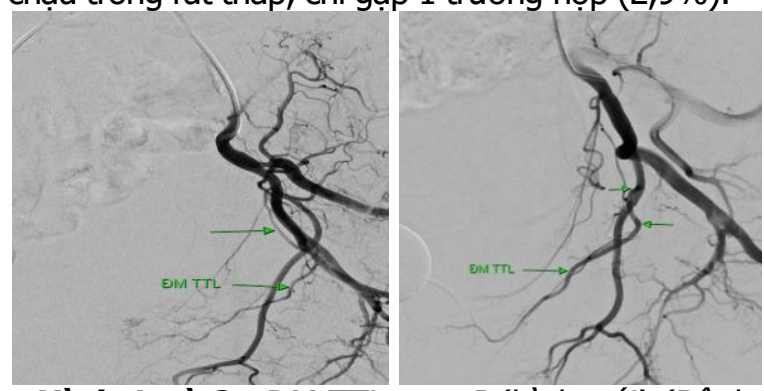

Hình 1 và 2. $Đ M T T L$ type I (hình trái) (Bệnh nhân 80 tuôii, chụp ngày 29/09/2020) và type III (hinh phải) (Bêenh nhân 63 tuổi, chụp ngày 16/04/2021). (Hinh ảnh chup tai khoa CĐHA Bênh viên Đại hơ Y Hà Nôii).

Trong các vị trí xuất phát của ĐM TTL, nhóm tách ra từ ĐM thẹn trong hay từ ĐM bịt là tương đối dễ chọn lọc vi ống thông vào $Đ M$ TTL, do góc xuất phát thuận lợi. Thường gặp khó khăn nhất là nhóm tách ra từ thân chung bàng quang, do khoảng thân chung giữa $Đ M$ bàng quang trên và bàng quang dưới thường rất ngắn, hơn nữa góc xuất phát thường ngược hướng, nhất là khi có kèm theo xơ vữa ngay đoạn gốc

Các vị trí xuất phát ít gặp hơn của ĐM TTL là ĐM trực tràng giữa, ĐM bịt lạc chỗ, ĐM mông trên, ĐM mông dưới, ĐM sinh dục phụ....1. Tuy nhiên, trong nghiên cứu này, tỉ lệ của tất cả các vị trí hiếm gặp lại tương đối cao (11.3\%).

Về số lượng ĐM TTL mỗi bên khung chậu: kết quả nghiên cứu của chúng tôi cũng tương đồng với các kết quả của Eldem và FC Carnevale ${ }^{2}$, ; trong đó, tỷ lệ gặp 02ĐM TTL từ cùng 1 bên khung chậu là tương đối hiếm $<10 \%$. Tuy nhiên, theo T. Bilhim, tỉ lệ này rất cao $43 \% \%^{5}$. Khi có 2 ĐM TTL ở một bên khung chậu, thì nhánh trước 
- trên thường xuất phát từ thân chung bàng quang và cấp máu cho phần trung tâm tuyến tiền liệt. Trong khi đó, nhánh sau - dưới thường xuất phát từ ĐM thẹn trong hay ĐM bịt, và cấp máu cho phần ngoại vi của tuyến.

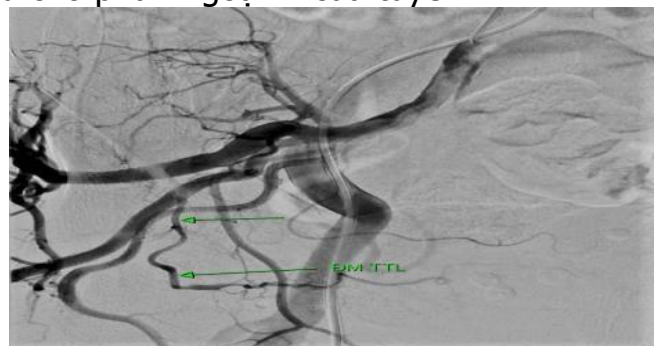

Hình 3. ĐM TTL type $V$, xuât phát từ ĐM mông dưới. (Hinh ảnh chụp tại khoa CĐHA Bệnh viện

Bạch Mai của bệnh nhân nam 61 tuổi, ngày 06/01/2021).

Về đường kính $Đ M \quad T T$, đường kính trung bình là $1.49 \pm 0,12 \mathrm{~mm}$, trong đó đường kính ĐM TTL nhỏ nhất là $0.61 \mathrm{~mm}$, lớn nhất là $3.6 \mathrm{~mm}$. Do đó, các loại vi ống thông được sử dụng cũng phải có kích thước nhỏ tương ứng.

Về hình dạng của ĐM TTL, không giống như vớiĐM tử cung luôn luôn có hình dạng xoắn vặ̆n như lò xo,ĐM TTL có hình ảnh lò xo chỉ gặp trong $77,4 \%$. Kết quả này cao hơn nhiều với nghiên cứu của T. Bilhim ${ }^{5}$. Trong khi đó, theo quan sátcủa chúng tôi, các hình ảnh này thường gặp ở các ĐM TTL có chiều dài ngắn, có gốc xuất phát gần với nhu mô tuyến hơn. Đây có thể coi đây là một dấu hiệu gợi ý tìm ĐM TTL trên phimchụp mạch số hóa xóa nền.

Một khó khăn khác trong quá trình can thiệp nút mạch TTL là xơ vữa. Xơ vữa ĐM TTL quan sát thấytrong $11,4 \%$, có thể gặp xơ vữa ở 1 vị trí hoặc nhiều vị trí.

Về vòng nối của ĐM TTL với các ĐM xung quanh, trong nghiên cứu của chúng tôi gặp ở 19 trường hợp,chiếm tỷ lệ $54,3 \%$. Tỷ lệ này cũng tương đồng với nghiên cứu của T. Bilhim (60\%), tuy nhiên tỷ lệ này lại chỉ chiếm $22,6 \%$ ở nghiên cứu của Wang ${ }^{3}, 5$. Trong nghiên cứu của chúng tôi, hay gặp nhất là vòng nối với động mạch TTL bên đối diện, qua các nhánh nuôi cho vùng trung tâm TTL $(37,1 \%)$. Điều này cũng phần nào lý giải cho thực tế là trong nhiều trường hợp, dù chỉ được nút mạch một bên, nhưng hiệu quả cũng không khác biệt nhiều so với nút được cả 2 bên ĐM TTL 6 .

Ngoài ra, các vòng nối khác đáng chú ý là với dương vật $(31,4 \%)$, bàng quang $(2,9 \%)$, trực tràng $(2,9 \%)$, túi tinh $(17,1 \%)$.

Đối với các trường hợp có 01 động mạch tuyến tiền liệt mỗi bên khung chậu, thường trước khi qua bao xơ tuyến tiền liệt, ĐM TTL tách ra nhánh trước bên cấp máu cho phần trung tâm tuyến, và nhánh sau bên cấp máu cho phần ngoại vi tuyến.

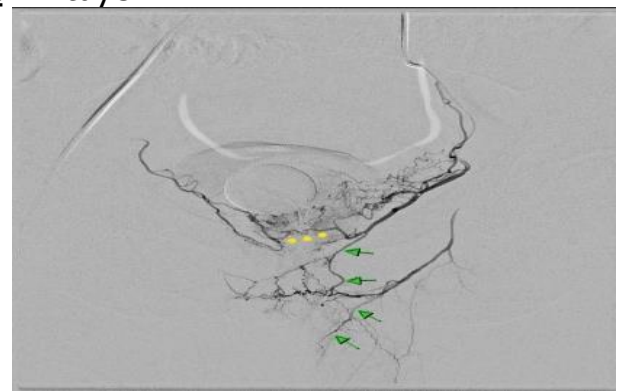

Hinh 4. ĐM TTL (mũi tên) cho nhánh cấp máu chogốc dương vật, ngoài ra còn cấp máu cho bên đối diện (chấm vàng). (Hình ảnh chụp tại khoa CĐHA Bệnh viện Đại học Y Hà Nội của bệnh nhân nam 62 tuôi, ngày 16/4/2021).

\section{KẾT LUÂ̂N}

Qua nghiên cứu kết quả chụp mạch của 20 bệnh nhân nam bị tăng sản lành tính TTL tại Khoa Chẩn đoán hình ảnh, bệnh viện đại học $Y$ Hà Nội, chúng tôi quan sát thây ĐM TTL xuất phát từ động mạch bịt là hay gặp nhất, tiếp theo là từ $Đ M$ thẹn trong và thân chung với ĐM bàng quang trên. Vòng nối ĐM TTL rất đa dạng, có thể cấp máu cho bàng quang, trực tràng, túi tinh, phần nhu mô TTL bên đối diện,.... Do đó, cần nắm vững giải phẫu và biến thể của ĐM TTL khi điều trị tăng sản lành tính tuyến tiền liệt bằng can thiệp nội mạch.

\section{TÀI LIẸU THAM KHẢO}

1. Xuan HN, Huy HD, Bich NNT, et al, (2019), Anatomical Characteristics and Variants of Prostatic Artery in Patients of Benign Hyperplasia Prostate by Digital Subtraction Angiography. Open Access Maced J Med Sci. 2019;7(24):4204-4208. doi:10.3889/oamjms. 361

2. FC Carnevale, A.M.d.A., Airton Mota Moreira, Vanessa Cristina de Paula Rodrigues et al, (2015). Pelvic arterial anatomy relevant to prostatic artery embolisation and proposal for angiographic classification. Cardiovascular and Interventional Radiological.

3. Wang MQ, Duan $F$, Yuan $K$, Zhang GD, Yan J et. Al, (2016). Benign prostatic hyperplasia: cone-beam CT in conjunction with DSA for identifying prostatic arterialanatomy. Radiology 2017; 282 (1): 271-280.doi: 10.1148/radiol. 152415.

4. Fatma Gonca ELDEM, Firat ATAK, Osman ÖÇAL, Ali Cansu BOZAÇ, Ahmet GỬELOĞLU, Bora PEYNİRCÍOGLU, (2021). Angiographic prostatic arterial anatomy in a Turkish population with benign prostatic hyperplasia. Turk J Med Sci 51: 518-522. 
doi:10.3906/sag-2004-289

5. Bilhim $T$, Pisco JM, Tinto $H R$, Fernandes $L$, Pinheiro LC, Furtado A, Casal D, Duarte M, Pereira J, Oliveira AG, O'Neill JE., (2012). Prostatic arterial supply: anatomic and imaging findings relevant for selective arterial embolization. Journal of Vascular and Interventional Radiology.
23(11):1403-15.

https://doi.org/10.1016/j.jvir.2012.07.028

PMid:23101913.

6. Pisco JM, Pinheiro LC, Bilhim T, Duarte M, Mendes JR, Oliveira AG., (2011). Prostatic arterial embolization to treat benign prostatic hyperplasia. JVascIntervRadiol; 22:11-19.

\section{TỔN THƯO'NG DA VÀ ĐAU CỦA NGƯỜI BÊNH UNG THƯ XẠ TRI TẠI BÊ̂NH VIÊ̂N 19 - 8 VÀ MộT SỐ YẾU TỐ LIÊN QUAN}

\section{TÓM TẮT}

Nghiên cứu thuân tâp được thực hiên trên nhóm người bênh ung thư có xạ trị tại Bệnh viện 19-8 nhằm (1) mô tả đặc điểm đau và tổn thương da của nhóm người bệnh tham gia nghiên cứu và (2) phân tích một số yếu tố liên quan đến đắc điểm tổn thương da. 264 người bệnh được đánh giá và theo dõi trong thời gian 2020-2021. Kểt quả: 70,8\% người bệnh ung thư được xạ trị có tổn thương da theo thang RTOG ở mức độ $1-2$ và rất ít tổn thương ở mức độ 3 . Không có tổn thương da ở mức độ 4 và 5 . Các biểu hiện thường gặp như ban đỏ,ngứa, rát da. Các triệu chứng hay xuất hiện trên da như cảm giác ấm nóng, rát da chiếm $33,3 \%$; ngứa và khó chịu trên da chiếm $27,1 \%$; đau/nhói như kim châm trên da chiếm 20,5\%. Triệu chứng đau của người bệnh ung thư trong quá trình xạ trị được báo cáo là 64,3\%. Nhóm người bệnh có thời gian điều trị trên 20 ngày, liều xạ trị trên 41 Gy, có nguy cơ tổn thương da cao hơn từ gấp 1,2 - 1,7 lần so với nhóm người bệnh còn lại. Kết luận: Cần chú ý chăm sóc và theo dối tổn thương da sớm trên nhóm người bệnh có thời gian chiếu tia liều cao và kéo dài

Tư khóa: Đau, tổn thương da, người bệnh ung thư có xạ trị.

\section{SUMMARY}

PAIN AND SKIN REACTION CHARACTERISTICS AMONG CANCER PATIENTS WITH RADIATION THERAPY AT 19-8 HOSPITAL AND SEVERAL ASSOCIATED FACTORS

Prospective study has been conducted among cancer with radiation therapy at 19-8 Hospital to (1) describle pain and skin reaction characteristics among study participants and (2) explore several associated factors on skin reaction characteristics. 264 patients had been evaluated and monitored during 2020 2021. Result: $70.8 \%$ of cancer patient with radiation therapy had skind reaction as level $1-2$ by RTOG and few patient wtih levels 3 of RTOG. Common skind

${ }^{1}$ Trường Đại học Y Hà Nội

²Bênh viên 19-8

Chịu trách nhiệm chính: Triệu Thị Minh

Email: trieuthiminh84ub198@gmail.com

Ngày nhận bài: 10/8/2021

Ngày phản biên luân án: 31/8/2021

Ngày duyệt bài: 29/9/2021

\section{Triệu Thị Minh ${ }^{1,2}$, Trương Quang Trung ${ }^{1}$}

symptoms include redness, itching, and burning. Symptoms often appear on the skin such as a feeling of warmth, burning accounting for $33.3 \%$; itching and discomfort on the skin accounted for $27.1 \%$; pain / stinging like needles on the skin accounted for $20.5 \%$. Pain symptoms of cancer patients during radiation therapy were reported in $64.3 \%$. The group of patients with treatment time over 20 days, radiation dose above $41 \mathrm{~Gy}$, had a higher relative risk of skin reaction from 1.2 to 1.7 times higher than the other group of patients. Conclusion: It is necessary to focus of caring and monitoring early skin lesions in the group of patients with high and prolonged exposure time.

Keyword: Pain, skin reaction characteristics, cancer patients with radiation therapy

\section{I. ĐẶT VẤN ĐỀ}

Ung thư là môt trong những nguyên nhân gây bệnh tật và tử vong trên toàn thế giới, có xu hướng ngày càng gia tăng, đặc biệt là các nước kém phát triển trong đó có Viêt Nam. Uớc tính rằng hơn $50 \%$ tổng số người bểnh ung thư được xa trị trong suốt quá trình mắc bênh của họ ${ }^{1}$. Các liệu pháp bức xạ được sử dụng trong điêu trị ung thư với mục đích điều trị triệt để, bổ trợ hoặc giảm nhẹ. Một số tác dụng phụ thường gặp trên người bệnh ung thư trong quá trình xạ trị như tốn thương da, mệt mỏi, buồn nôn, chán ăn, rụng tóc, viêm niêm mạc miệng... [2],[3]. Các phản ứng da do bức xạ hoặc viêm da bức xạ được báo cáo trong $95 \%$ trường hợp ung thư người bệnh đang xạ trị (RT)[4]. Những thay đổi trên da và đau trong quá trình xạ trị là những tác dụng phụ không mong muốn, có thể ảnh hưởng đến chất lượng cuộc sống cũng như thẩm mỹ của người bệnh bao gồm ngứa, rát, sạm da, tróc vảy khô, bong trợt da, loét da...

Nguyên đơn Xạ trị thuộc Trung tâm Ung bướu BV 19-8 sử dụng máy xạ gia tốc tuyến tính Eleckta Prise thực hiện các kỹ thuật chiếu xạ 3D, IMRT với số lượng trung bình 35 - 45 người bênh hàng tháng và từ 600-900 lượt chiếu xạ. Đánh giá và phát hiện sớm biểu hiện tổn thương da và mức độ trong quá trình xạ trị giúp cho nhân viên 